\title{
One-pot tandem cyclization of enantiopure asymmetric cis-2,5-disubstituted pyrrolidines: Facile access to chiral 10-heteroazatriquinanes
}

\author{
Ping-An Wang ${ }^{*}$, Sheng-Yong Zhang ${ }^{1}$ and Henri B. Kagan ${ }^{2}$
}

\section{Full Research Paper}

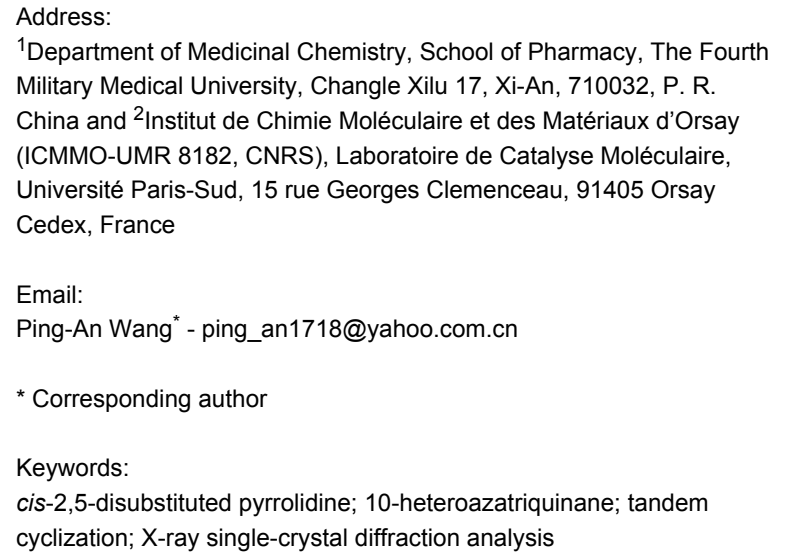

Beilstein J. Org. Chem. 2013, 9, 265-269.

doi:10.3762/bjoc.9.32

Received: 12 October 2012

Accepted: 16 January 2013

Published: 07 February 2013

Associate Editor: B. Stoltz

(C) 2013 Wang et al; licensee Beilstein-Institut. License and terms: see end of document.

\begin{abstract}
A series of chiral 10-heteroazatriquinanes were synthesized from enantiopure asymmetric cis-2,5-disubstituted pyrrolidines through a one-pot tandem cyclization procedure. The structures and configurations of these new chiral 10-heteroazatriquinanes are confirmed by X-ray single-crystal diffraction analysis.
\end{abstract}

\section{Introduction}

The azatriquinane derivatives are an important substance class in organic chemistry containing nitrogen and three fused fivemembered rings [1-3]. Due to the unique rigid bowl-shaped structure with one noninversible electron lone pair at the bottom of the central nitrogen ("centro-N") atom, 10-azatriquinane analogues are used as efficient chelation reagents of metal cations [4,5]. Mascal and colleagues [6] described the first synthesis of 10-azatriquinane (1) from dimethyl 3,3'-(1H-pyrrole2,5-diyl)dipropanoic acid in five steps, and the reactivity of $\mathbf{1}$ was also investigated. 10-azatriquinane (1) is very active because of its high basicity. The X-ray structure of $\mathbf{1} \cdot \mathrm{HBF}_{4}$ revealed that the centro- $\mathrm{N}$ is pyramidalized. 10-azatriquinacene (2), an unsaturated analogue of $\mathbf{1}$, was attractive due to its high proton affinity [7]. Recently, Mascal [8] and colleagues have developed a series of 10 -azatriquinanes as a $C_{3 v}$-symmetric platform for tripodal metal complexes and calixiform scaffolds (Figure 1).

Previously, we established a facile access to enantiopure asymmetric cis-2,5-disustituted pyrrolidines 4 from commercially available starting materials diethyl meso-2,5-dibromoadipate and $(S)-(-)-1$-phenylethylamine (Figure 2) [9]. The preparations of compounds $5 \mathbf{a}, \mathbf{5 b}, \mathbf{6 a}$ and $\mathbf{6 b}$ were also reported in [9], but our previously published structures for compounds $\mathbf{5 a}$ and 5b were not completely correct, because the B-N dative bonds were missing. The aim of the following procedures was to 


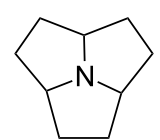

1

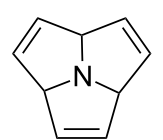

2

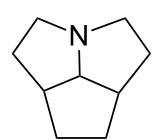

3 10-azatriquinane 10-azatriquinacene 1-azatriquinane
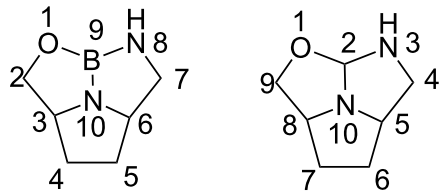

10-heteroazatriquinane derivatives (this work)

Figure 1: The structures of azatriquinanes and azatriquinacene.

obtain several novel bifunctional $N$-hetereocyclic carbenes (NHCs) [10-14] from compounds 4 through three steps, including reduction, debenzylation and cyclization (Scheme 1), but this failed. However, we have found a novel one-pot tandem cyclization of these enantiopure asymmetric cis-2,5-disubstituted pyrrolidines to produce chiral trisubstituted 10-heteroazatriquinane derivatives. To the best of our knowledge, there is very little research on the synthesis of 10-heteroazatriquinanes, and the chiral 10-heteroazatriquinanes are unknown up to now.

\section{Results and Discussion}

For the reduction of highly hindered amides 4 , the system of $\mathrm{LiAlH}_{4}$ in anhydrous THF was found to be useless even upon

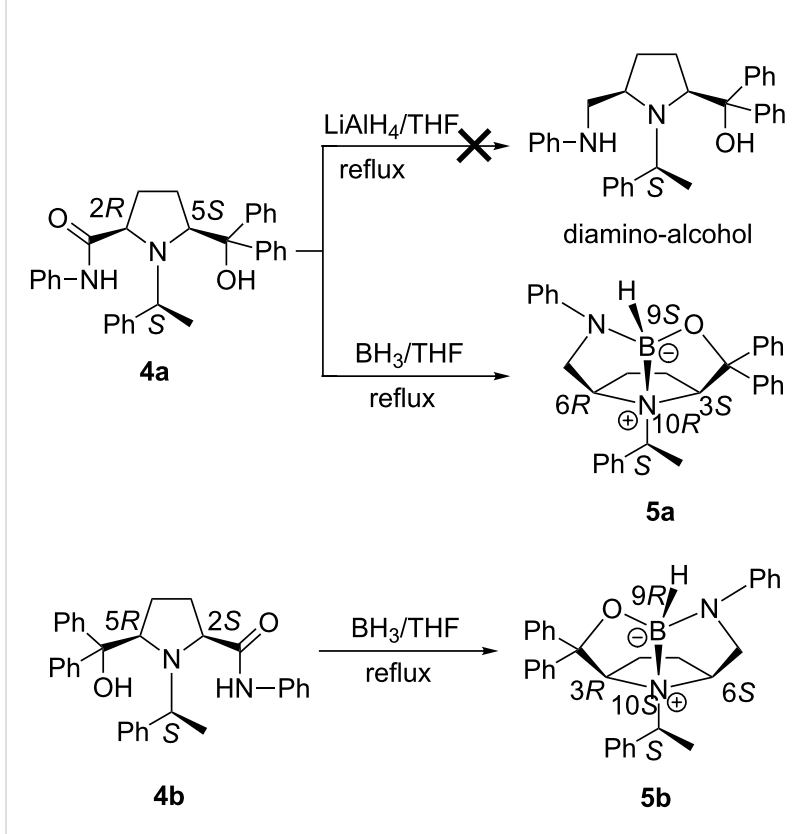

Scheme 2: The reduction of amides 4 by $\mathrm{LiAlH}_{4}$ and $\mathrm{BH}_{3} \cdot \mathrm{THF}$.

heating under reflux for $18 \mathrm{~h}$ under an inert atmosphere, and no desired diamino-alcohols were obtained after workup. However, 4a reacted smoothly with $\mathrm{BH}_{3}$ to give white crystals after chromatographic purification (Scheme 2). The X-ray singlecrystal diffraction analysis established that the reduction product 5a (Figure 3) was formed with a rigid 10-heteroaza-<smiles>CC#CCC</smiles>

meso-

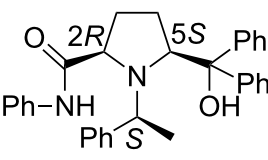

$4 a$

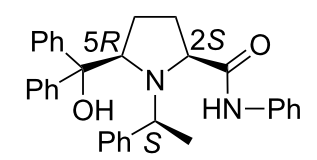

$4 b$

Figure 2: The synthesis of $\mathbf{4}$ (previous work)

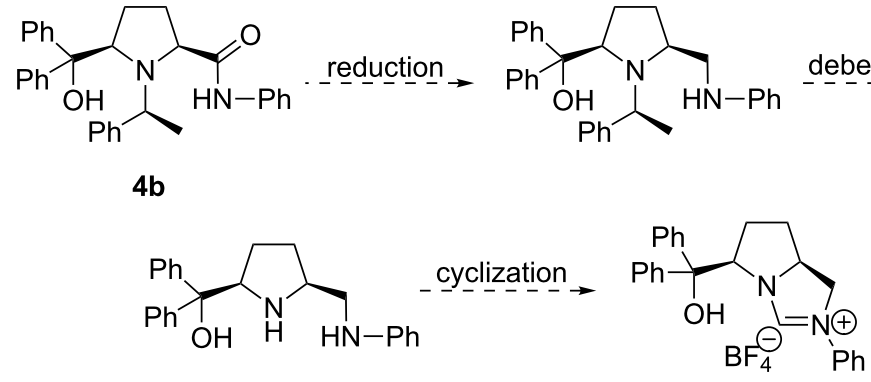

NHC 


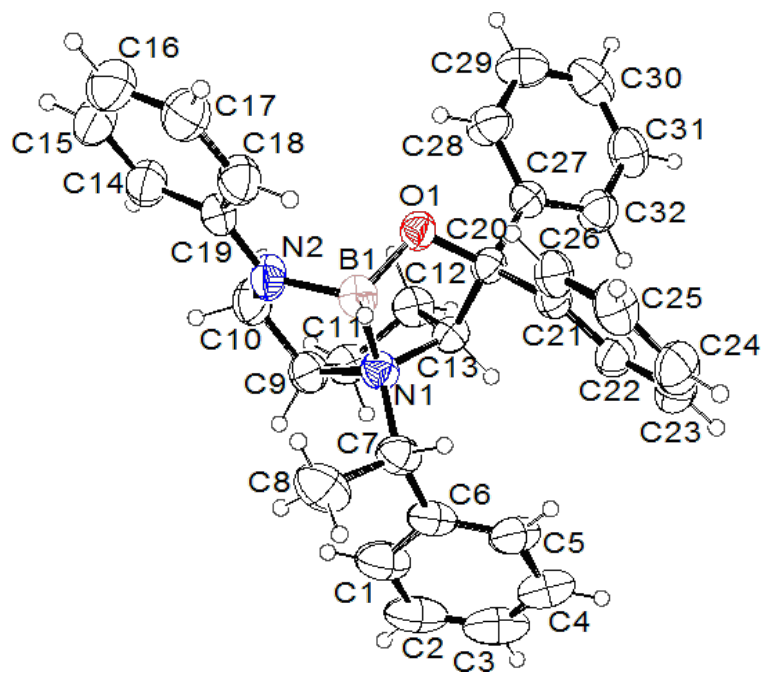

Figure 3: X-ray crystal structure of compound $\mathbf{5 a .}$

quinane skeleton through an intramolecular Lewis acid-base pair interaction [15-18]. Three five-membered rings are fused to give a very stable bowl-shaped tricyclic system with five stereogenic centers, especially for one chiral nitrogen center and one chiral boron center. The configurations of the stereogenic centers in 5a are deduced from the configuration of the chiral auxiliary (S)-(-)-1-phenylethylamine to be $S, 3 S, 6 R, 9 S$ (chiral $\mathrm{B}$ atom) and $10 R$ (chiral $\mathrm{N}$ atom), respectively. This novel tandem reduction/cyclization was made possible by the cis-configuration of the starting 2,5-disubstituted pyrrolidine 4a. Following the same procedure, 10 -heteroazaquinane $\mathbf{5 b}$ was obtained in good yield (87\%), and the configurations of 5b were assigned to be $S, 3 R, 6 S, 9 R$ (chiral B atom) and $10 S$ (chiral $\mathrm{N}$ atom), respectively. Compounds $\mathbf{5 a}$ and $\mathbf{5 b}$ are diastereomers.

In the presence of a catalytic amount of $\mathrm{Pd}(\mathrm{OH})_{2} / \mathrm{C}$, under $1.0 \mathrm{~atm}$ of hydrogen, the above 10-heteroazaquinane derivatives 5 were converted into enantiopure asymmetric cis-2,5disubstituted pyrrolidines 6 in good yields with a diaminoalcohol skeleton. In this process, both $N$-debenzylation and a ring-opening reaction occurred. Diamino-alcohols $6 \mathbf{a}$ and $\mathbf{6 b}$ are enantiomers, and they can serve as precursors for the synthesis of hydroxy $N$-heterocyclic carbenes. Following the reported procedure for the preparation of $N$-heterocyclic carbenes $[19,20]$, the enantiopure pyrrolidine $\mathbf{6 b}$ and $\mathrm{NH}_{4} \mathrm{BF}_{4}$ in $\mathrm{HC}\left(\mathrm{OCH}_{3}\right)_{3}$ is heated to $80{ }^{\circ} \mathrm{C}$ for $2 \mathrm{~h}$, the light yellow crystals were obtained in good yield after workup (Scheme 3 ). The same result was obtained by heating the mixture of $\mathbf{6 b}, \mathrm{NH}_{4} \mathrm{BF}_{4}$ and $\mathrm{HC}\left(\mathrm{OCH}_{3}\right)_{3}$ in anhydrous toluene under reflux.

To our delight, a single crystal was grown from $\mathrm{CH}_{2} \mathrm{Cl}_{2}$, suitable for X-ray diffraction analysis. It was found that the ringclosing reaction took place during the heating process following $\mathrm{N}$-methylation to provide the rigid 1-oxo-3-aza-10-azaquinane skeleton $\mathbf{7 b}$ as its ammonium salt. Compound $\mathbf{7 b}$ contains four stereogenic centers, and their configurations are assigned to be $2 R, 5 S, 8 R$ and $10 R$ (chiral $\mathrm{N}$ atom) based on its starting material 4b (Figure 4). Actually, $\mathrm{HC}\left(\mathrm{OCH}_{3}\right)_{3}$ as an efficient reagent for $\mathrm{C}$-, $\mathrm{N}$-, and $\mathrm{O}$-methylation has been reported [21$24]$, but the mechanism of these methylations is elusive. The other chiral ammonium salt 7a was obtained under the same

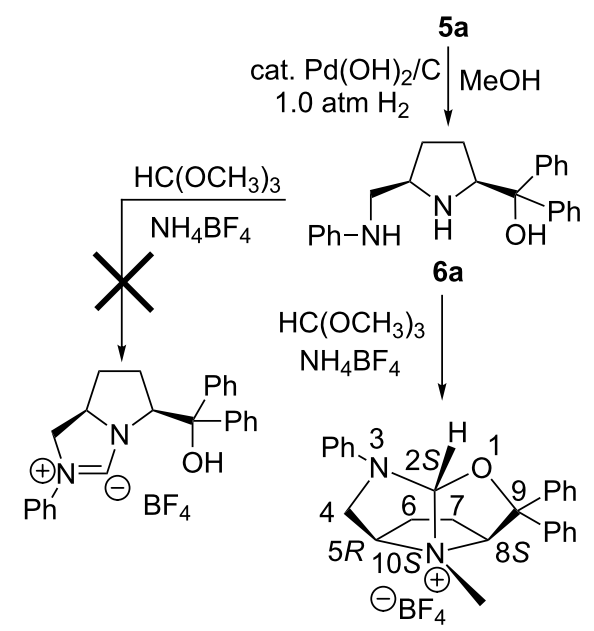

$7 \mathbf{a}$

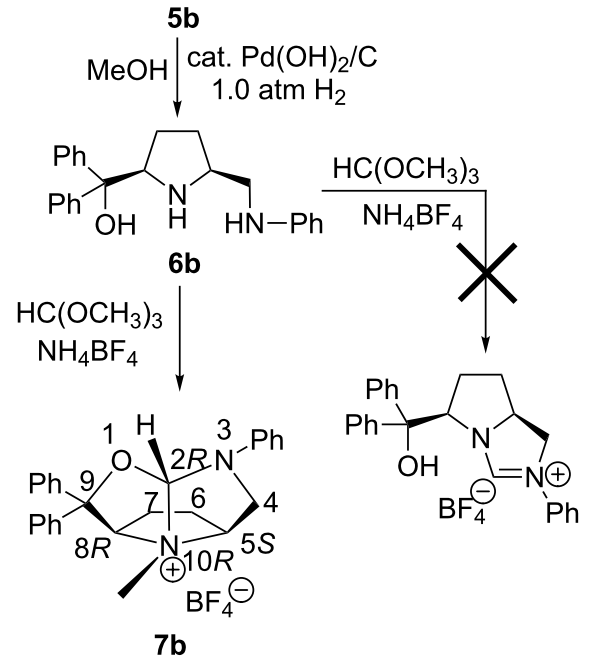


conditions as those for the preparation of $7 \mathbf{b}$. The chiral ammonium salts $7 \mathbf{a}$ and $\mathbf{7 b}$ were derived from the enantiomers $\mathbf{6 a}$ and $\mathbf{6 b}$, therefore, $\mathbf{7 a}$ and $\mathbf{7 b}$ are also enantiomers. The configurations of $7 \mathbf{a}$ are assigned to be $2 S, 5 R, 8 S$ and $10 S$ (chiral $\mathrm{N}$ atom).

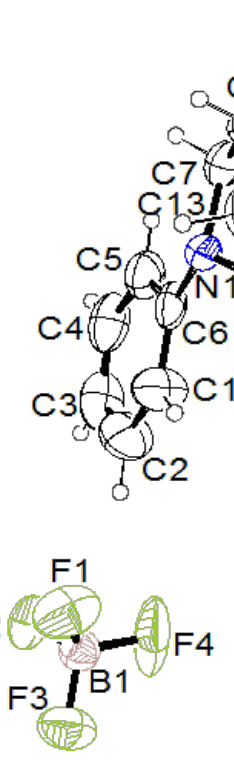

Figure 4: X-ray crystal structure of compound $7 \mathrm{~b}$.

As shown in Figure 4, this 10-heteroazatriquinane $7 \mathbf{b}$ possesses a rigid bowl-like molecular scaffold with a quaternary nitrogen site (N2) at the bottom of the cavity. Recently, Denmark and colleagues $[25,26]$ have synthesized a series of chiral phasetransfer catalysts (chiral PTCs) based on a 2-azatriquinane skeleton (Figure 5), and they have investigated their catalytic activities in asymmetric alkylation reactions for producing enantiomerically enriched amino acids. The synthesis of these quaternary ammonium ions follows a diversity-oriented approach wherein the tandem inter-[4+2]/intra-[3+2] cycloaddition of nitroalkenes serves as the key transformation. The chiral ammonium salts 7 have a structure similar to the chiral PTCs of Denmark et al. The substituents in the chiral ammonium salts 7 are easily tunable, which could open a route to various chiral PTCs for organic synthesis.

\section{Conclusion}

In summary, we provide here a facile access to chiral 10-heteroazatriquinanes from enantiopure asymmetric cis-2,5-disubstituted pyrrolidines through one-pot tandem cyclization reactions, and their configurations are confirmed by X-ray single-crystal diffraction analysis. The applications of these novel 10-heteroazatriquinanes are currently being investigated in our laboratory.

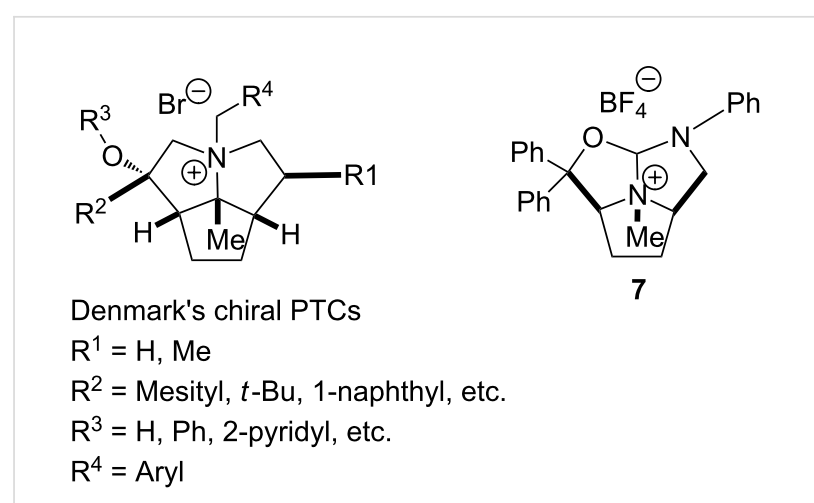

Figure 5: The structural comparison of chiral ammonium salts such as 7 with the chiral PTCs of Denmark et al.

\section{Supporting Information}

\section{Supporting Information File 1}

Full experimental details, analytical data and crystallographic information.

[http://www.beilstein-journals.org/bjoc/content/ supplementary/1860-5397-9-32-S1.pdf]

\section{Acknowledgements}

We would like to thank the National Science Foundation of China (No. 20802092) and the Young Scholar Foundation of the Fourth Military Medical University (FMMU, China) for financial support of this work. P. A. Wang also thanks the Centre National de la Recherche Scientifique (CNRS, France) for a postdoctoral fellowship to work in the Laboratoire de Catalyse Moléculaire in the ICMMO, Université Paris-Sud.

\section{References}

1. Mascal, M.; Lera, M.; Blake, A. J. J. Org. Chem. 2000, 65, 7253-7255. doi:10.1021/jo005571o

2. Mascal, M.; Hafezi, N.; Meher, N. K.; Fettinger, J. C. J. Am. Chem. Soc. 2008, 130, 13532-13533. doi:10.1021/ja805686u

3. Mascal, M.; Hext, N. M.; Shishkin, O. V. Tetrahedron Lett. 1996, 37, 131-134. doi:10.1016/0040-4039(95)02091-8

4. Jiao, H. J.; Halet, J.-F.; Gladysz, J. A. J. Org. Chem. 2001, 66, 3902-3905. doi:10.1021/jo001800v

5. Gussenhoven, E. M.; Jevric, M.; Olmstead, M. M.; Fettinger, J. C.; Mascal, M.; Balch, A. L. Cryst. Growth Des. 2009, 9, 1786-1792. doi:10.1021/cg800906x

6. Hext, N. M.; Hansen, J.; Blake, A. J.; Hibbs, D. E.; Hursthouse, M. B.; Shishkin, O. V.; Mascal, M. J. Org. Chem. 1998, 63, 6016-6020. doi:10.1021/jo980788s

7. Mascal, M. J. Org. Chem. 2007, 72, 4323-4327. doi:10.1021/jo070043z

8. Jevric, M.; Zheng, T.; Meher, N. K.; Fettinger, J. C.; Mascal, M. Angew. Chem., Int. Ed. 2011, 50, 717-719. doi:10.1002/anie.201006470 
9. Wang, P.-A.; Xu, Z.-S.; Chen, C.-F.; Gao, X.-G.; Sun, X.-L.; Zhang, S.-Y. Chirality 2007, 19, 581-588. doi:10.1002/chir.20424

10. He, L.; Zhang, Y. R.; Huang, X. L.; Ye, S. Synthesis 2008, 17, 2825-2829. doi:10.1055/s-2008-1067216

11.Lv, H.; Chen, X.-Y.; Sun, L.-h.; Ye, S. J. Org. Chem. 2010, 75, 6973-6976. doi:10.1021/jo101318u

12. Huang, X.-L.; Chen, X.-Y.; Ye, S. J. Org. Chem. 2009, 74, 7585-7587. doi:10.1021/jo901656q

13. Zhang, Y.-R.; He, L.; Wu, X.; Shao, P.-L.; Ye, S. Org. Lett. 2008, 10 , 277-280. doi:10.1021/ol702759b

14. Wang, X.-N.; Shao, P.-L.; Lv, H.; Ye, S. Org. Lett. 2009, 11, 4029-4031. doi:10.1021/ol901290z

15. Zhu, L.; Shabbir, S. H.; Gray, M.; Lynch, V. M.; Sorey, S.; Anslyn, E. V. J. Am. Chem. Soc. 2006, 128, 1222-1232. doi:10.1021/ja055817c

16. Tsurumaki, E.; Saito, S.; Kim, K. S.; Lim, J. M.; Inokuma, Y.; Kim, D.; Osuka, A. J. Am. Chem. Soc. 2008, 130, 438-439. doi:10.1021/ja078042b

17. Stepanenko, V.; De Jesús, M.; Correa, W.; Bermúdez, L.; Vázquez, C.; Guzmán, I.; Ortiz-Marciales, M. Tetrahedron: Asymmetry 2009, 20, 2659-2665. doi:10.1016/j.tetasy.2009.11.009

18. Montalbano, F.; Candeias, N. R.; Veiros, L. F.; André, V.; Duarte, M. T.; Bronze, M. R.; Moreira, R.; Gois, P. M. Org. Lett. 2012, 14, 988-991. doi:10.1021/ol203224n

19. Funk, T. W.; Berlin, J. M.; Grubbs, R. H. J. Am. Chem. Soc. 2006, 128, 1840-1846. doi:10.1021/ja055994d

20. Van Veldhuizen, J. J.; Gillingham, D. G.; Garber, S. B.; Kataoka, O.; Hoveyda, A. H. J. Am. Chem. Soc. 2003, 125, 12502-12508. doi:10.1021/ja0302228

21. Janin, Y. L.; Huel, C.; Flad, G.; Thirot, S. Eur. J. Org. Chem. 2002, 1763-1769. doi:10.1002/1099-0690(200206)2002:11<1763::AID-EJOC1763>3.0.C $\mathrm{O} ; 2-\mathrm{Q}$

22. Selva, M.; Tundo, P. J. Org. Chem. 1998, 63, 9540-9544. doi:10.1021/jo980914s

23. Padmanabhan, S.; Reddy, N. L.; Durant, G. J. Synth. Commun. 1997, 27, 691-699. doi:10.1080/00397919708003343

24. Kumar, H. M. S.; Reddy, B. V. S.; Mohanty, P. K.; Yadav, J. S. Tetrahedron Lett. 1997, 38, 3619-3622. doi:10.1016/S0040-4039(97)00684-9

25. Denmark, S. E.; Gould, N. D.; Wolf, L. M. J. Org. Chem. 2011, 76, 4260-4336. doi:10.1021/jo2005445

26. Denmark, S. E.; Gould, N. D.; Wolf, L. M. J. Org. Chem. 2011, 76, 4337-4357. doi:10.1021/jo2005457

\section{License and Terms}

This is an Open Access article under the terms of the Creative Commons Attribution License

(http://creativecommons.org/licenses/by/2.0), which permits unrestricted use, distribution, and reproduction in any medium, provided the original work is properly cited.

The license is subject to the Beilstein Journal of Organic Chemistry terms and conditions:

(http://www.beilstein-journals.org/bjoc)

The definitive version of this article is the electronic one which can be found at:

doi:10.3762/bjoc.9.32 